\title{
Fuzzy C-Means with Stepwise Level Slice Processing for Water Quality Analysis in Lake Hachiroko
}

\author{
Kai Matsui, Yoichi Kageyama*, Hiroshi Yokoyama \\ Aktia University, 1-1 Tegata Gakuen-machi, Akita-shi, Akita 010-8502, Japan \\ *Corresponding Author: kageyama@ie.akita-u.ac.jp
}

\begin{abstract}
Changes in water quality in rivers and lakes caused by water pollution are generally investigated by extracting water samples directly from several locations. However, this method is not appropriate for understanding water quality conditions over a large area. On the other hand, remote sensing techniques are especially suitable for understanding water quality conditions over a large area. In our previous studies, we applied fuzzy c-means (FCM) clustering for analysis of water quality parameters in Lake Hachiroko. The results indicated that FCM was effective in estimating the level of pollution in Lake Hachiroko. Moreover, we considered the setting of the best initial values in FCM. The result showed that estimation maps by FCM showed detailed water quality conditions in Lake Hachiroko. However, some estimation maps were classified at the same level in the whole region because the slice level range preset was too wide. The estimation maps created by FCM were in agreement with the water quality conditions, while identifying the water pollution area in the lake was difficult. In this study, we proposed stepwise level slice processing to create water quality estimation maps by FCM. As a result, FCM with stepwise level slice processing (i) creates water quality estimation maps that identify the pollution area and (ii) is useful for water quality estimation of Lake Hachiroko.
\end{abstract}

Keywords: remote sensing, fuzzy c-means, water quality

\section{Introduction}

Changes in water quality in rivers and lakes caused by water pollution are generally investigated by extracting water samples directly from several locations. However, this method can obtain only local information and is not appropriate for understanding water quality conditions over a large area. Therefore, remote sensing techniques have been used to analyze water quality, and these techniques are especially suitable for understanding water quality conditions over a large area ${ }^{(1-4)}$. The use of remote sensing data of a large area can identify water pollution areas ${ }^{(1)}$. Moreover, remote sensing can acquire multispectral information of a target. Analysis of this information can be useful to the investigation of the causes of water pollution.

In our previous studies, we applied fuzzy c-means (FCM) clustering for analysis of water quality parameters in Lake Hachiroko ${ }^{(2-4)}$. This method considers the effects of specific disturbances and uncertainties on remote sensing data. The results indicated that FCM was effective in estimating the level of pollution in Lake Hachiroko(2). In addition, we worked to understand the water quality parameters that have a strong relationship with the estimation maps by FCM, using multi-temporal remote sensing data ${ }^{(3)}$. As a result, it became clear that the estimation maps obtained by FCM were particularly useful for determining suspended solid (SS) amounts in the water quality analysis.

Although the initial values given to the classes used in FCM affect the results of FCM, the setting of the best initial values had not been studied. Furthermore, estimation maps by FCM, which were classified into six levels based on the environmental standard value ${ }^{(5)}$ made it difficult to decipher the water quality situation because of the levels were too detailed depending on the values of water quality parameters in the lake ${ }^{(3)}$. To create the estimation map according to the water quality levels in the lake, we studied the setting of the initial values in FCM using water quality data synchronized with observation times of remote sensing data. As a result, the estimation maps by FCM showed detailed water quality conditions in Lake Hachiroko. 
However, some estimation maps were classified at the same level in the whole region because the set slice level range was too wide ${ }^{(4)}$. The estimation maps created by FCM were in agreement with the water quality conditions. On the other hand, identifying water pollution areas in the lake was difficult. Therefore, slice level processing that affects water quality estimation maps created by FCM need to be considered. However, changing of the slice levels for each set of data makes difficult to compare between the estimation maps using the data obtained different dates Moreover, the estimation maps by FCM with increasing slice levels are difficult to decipher because of too much detail depending on the water quality data.

In this study, we proposed stepwise level slice processing to create water quality estimation maps by FCM. In the case that water quality values of all measurement sites in the water quality data are included in one slice level, the level is divided equally at a new slice level value. By performing level slice processing with steps, water quality estimation maps are created without changing the slice level values too much. To evaluate the usefulness of FCM, we compared the estimation maps with the water quality data.

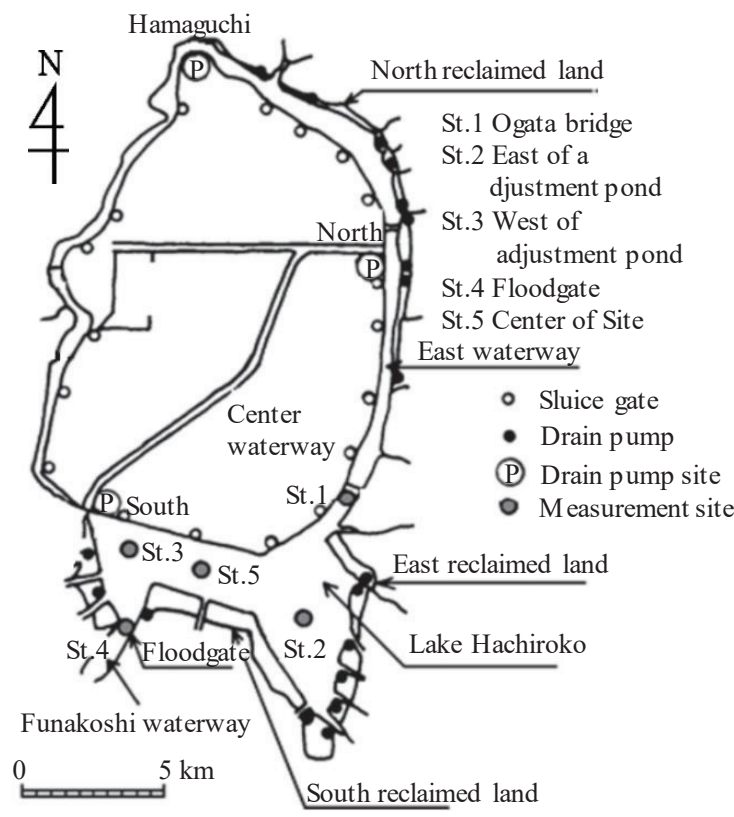

Fig. 1. Outline of Lake Hachiroko and the water quality measurement sites (St. 1 to St. 5).

\section{Study Area}

Lake Hachiroko is located approximately $20 \mathrm{~km}$ north of Akita, Japan, and is a freshwater lake with a center latitude of $40^{\circ} \mathrm{N}$ and longitude of $140^{\circ} \mathrm{E}$. More than 20 rivers flow into the lake. The annual water flow, including rainfall, into the lake is approximately $1.2 \mathrm{~km}^{3}$, and almost the same volume of water flows out from the floodgate to the Sea of Japan. Furthermore, water pollution has become a significant problem in the lake because of incoming agricultural drainage. Green algae blooms occur during the summer $^{(6)}$. Thus, since 2007, the lake has been designated part of the "Act on Special Measures Concerning Conservation of Lake Water Quality ${ }^{(5)}$." Therefore, it is necessary to understand the details of the surface water quality of the lake and how these are affected by the seasons. Fig. 1 shows an outline of Lake Hachiroko and the water quality measurement sites, denoted as St. 1 to St. 5. According to experts on water quality in the study area, it is likely that the east side of the adjustment pond, which receives polluted water from nearby rivers, will become polluted.

\section{Materials}

\subsection{ASTER Data}

The ASTER data used for analysis constitute three spectral bands at visible (green and red) and near-infrared wavelengths and have a resolution of $15 \mathrm{~m}$. The approximate scene size is a $60 \mathrm{~km}$ wide swath. In this study, data recorded on June 3, 2004; August 5, 2012; September 13, 2012; and May 26, 2015 (called "June data," "August data," "September data," and "May data," respectively) were used for analysis. Fig. $2^{(7)}$ shows images obtained by Terra ASTER.

\subsection{Water Quality Measurements}

Environmental quality parameters are constantly reviewed and updated by the Akita Prefectural Government. From these, five water quality parameters were used for our analysis, namely biochemical oxygen demand (BOD), chemical oxygen demand (COD), SS, total nitrogen (T-N), and total phosphorus (T-P). We selected water quality measurements recorded on June 2, 2004; August 1, 2012; September 13, 2012; and May 19, 2015 ${ }^{(5)}$. These data were obtained from the five measurement sites in Lake Hachiroko and synchronized with observation times of 
remote sensing data. There was no rainfall when measurement of water quality and collection of remote sensing data were conducted ${ }^{(8)}$.

\section{Data Analysis}

\subsection{Process for Analysis}

Fig. 3 shows the process of creation of estimation maps by FCM. First, we performed atmospheric correction to remove atmospheric effects from the ASTER data. Subsequently, mask processing was performed to detect the water areas in the study area. To perform FCM, the initial values in FCM were set using ASTER data and water quality data. After that, we applied FCM to the extracted area to calculate the degrees of belonging to each class. To obtain the estimation maps, we applied the proposed stepwise level slice processing to the obtained degrees of belonging. In addition, to evaluate the usefulness of FCM, we compared the estimation maps with the water quality data.

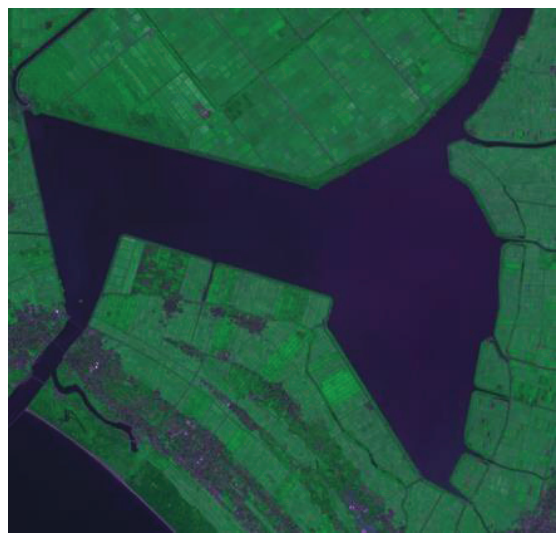

(a) September data.

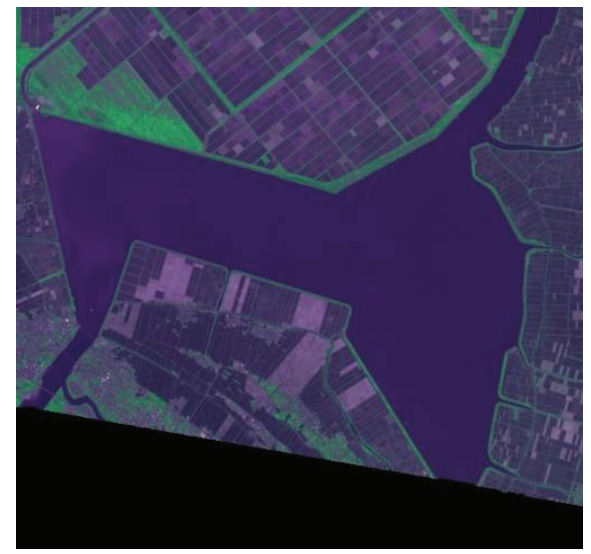

(b) May data.

Fig. 2. Terra ASTER data (RGB: Bands 2, 3, and 1). (citation: ASTER-VA image courtesy of NASA/METI/AIST/Japan Spacesystems, and U.S./Japan ASTER Science Team)

\subsection{Estimation Maps Created by FCM}

\subsubsection{The Initial Values Setting in FCM}

We classified the study area into two classes (Class 1 and Class 2), which are locations with the relatively lowest and highest pollution points in the study area using FCM. $\mathrm{C}_{1}$ and $\mathrm{C}_{2}$ were defined from the center value of Class 1 and Class 2, respectively. To perform classification by FCM, it is necessary to set the initial values to $\mathrm{C}_{1}$ and $\mathrm{C}_{2}$. The procedure of initial values setting of $\mathrm{FCM}^{(4)}$ is as follows:

(1) Change the water quality data to the slice levels based on the environmental standard value ${ }^{(5)}$. Slice levels are listed in Table 1.

(2) Select the water quality measurement sites with the minimum slice level $\left(\mathrm{L}_{\mathrm{C} 1}\right)$ and maximum slice level $\left(\mathrm{L}_{\mathrm{C} 2}\right)$ in the water quality data. The selected sites are defined as $\mathrm{S}_{\mathrm{C} 1}$ and $\mathrm{S}_{\mathrm{C} 2}$.

(3) Take a sample of $\mathrm{DN}$ values in 50 points from $\mathrm{S}_{\mathrm{C} 1}$ and $\mathrm{S}_{\mathrm{C} 2}$ in the ASTER data.

(4) Set the means of the sampled DN values as the initial values of $\mathrm{C}_{1}$ and $\mathrm{C}_{2}$.

\subsubsection{FCM}

Remote sensing data include specific disturbances such as noise from the measurement system, and it is necessary to consider each instance of fuzziness in the data. FCM, a kind of clustering method, was used to consider fuzziness in the remote sensing data ${ }^{(2-4)}$. An FCM flowchart is shown in Fig. 4. The weight coefficient $m$

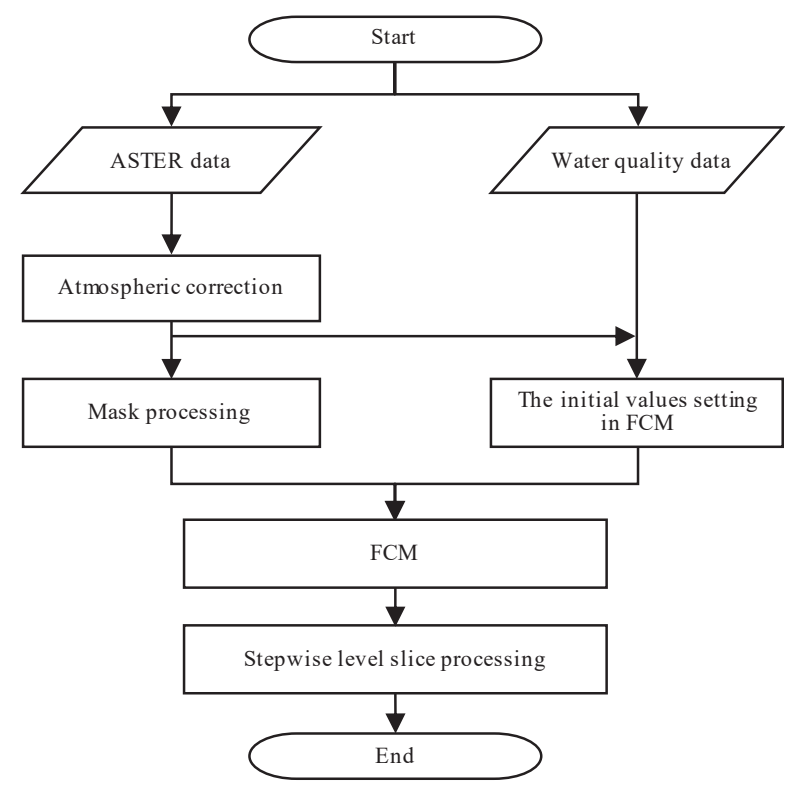

Fig. 3. Flowchart of creation estimation maps by FCM. 
was set at 2 because it changes from 2 to 10 at an interval of 0.1 . The clustering process stops when the number of moving pixels between the two classes reaches $1 \%$ or less of the total number of pixels.

\subsubsection{Stepwise Level Slice Processing}

To obtain estimation maps, level slice processing was performed. The degree of belonging of Class 2 was divided into $\mathrm{L}_{\mathrm{C} 1}$ to $\mathrm{L}_{\mathrm{C} 2}$ at equal intervals. However, in the case that

Table 1. Slice level based on the environmental standard value ${ }^{(5)}$.

\begin{tabular}{|c|r|r|r|r|c|}
\hline \multirow{2}{*}{ Slice level } & \multicolumn{5}{|c|}{ Water quality parameters } \\
\cline { 2 - 6 } & $\begin{array}{c}\text { BOD } \\
(\mathrm{mg} / \mathrm{l})\end{array}$ & $\begin{array}{c}\text { COD } \\
(\mathrm{mg} / \mathrm{l})\end{array}$ & $\begin{array}{c}\text { SS } \\
(\mathrm{mg} / \mathrm{l})\end{array}$ & $\begin{array}{c}\text { T-N } \\
(\mathrm{mg} / \mathrm{l})\end{array}$ & $\begin{array}{c}\text { T-P } \\
(\mathrm{mg} / \mathrm{l})\end{array}$ \\
\hline 1 & $0-1.0$ & $0-1.0$ & $0-1$ & $0-0.10$ & $0-0.005$ \\
\hline 2 & $1.0-2.0$ & $1.0-3.0$ & $1-5$ & $0.10-0.20$ & $0.005-0.010$ \\
\hline 3 & $2.0-3.0$ & $3.0-5.0$ & $5-15$ & $0.20-0.40$ & $0.010-0.030$ \\
\hline 4 & $3.0-5.0$ & $5.0-8.0$ & $15-25$ & $0.40-0.60$ & $0.030-0.050$ \\
\hline 5 & $5.0-8.0$ & $8.0-12.0$ & $25-35$ & $0.60-1.00$ & $0.050-0.100$ \\
\hline 6 & $8.0-$ & $12.0-$ & $35-$ & $1.00-$ & $0.100-$ \\
\hline
\end{tabular}

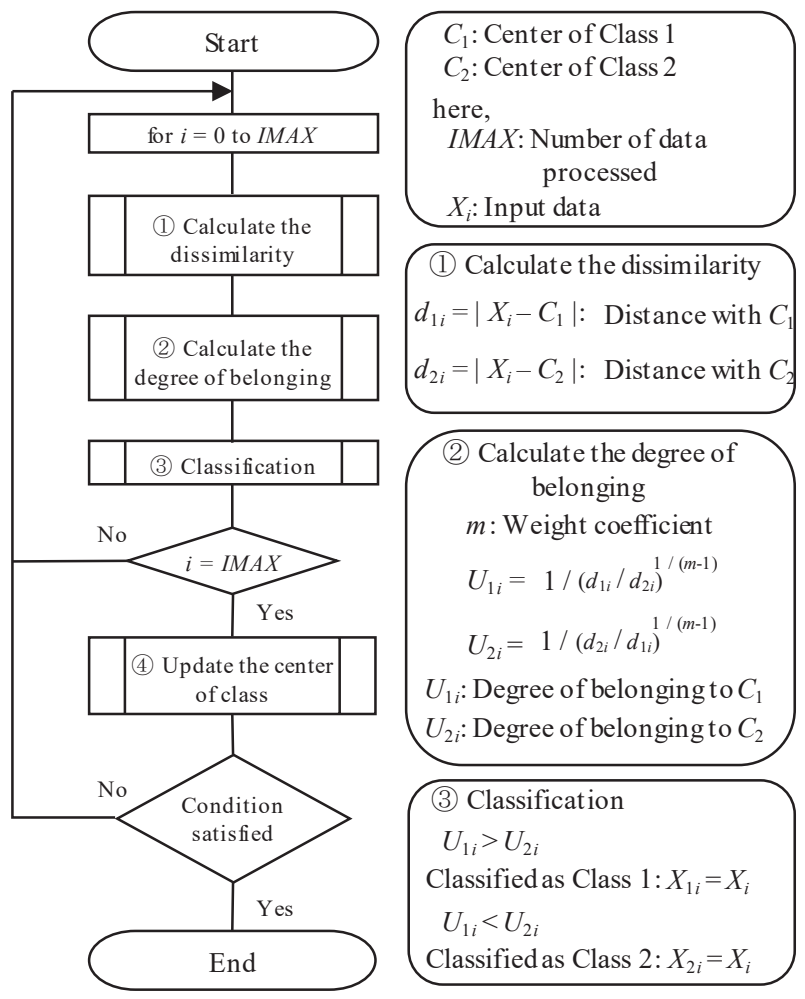

\begin{tabular}{lll} 
(4) Update the center of class & \\
$C_{1}=\sum_{i=0}^{I_{1 i}} U_{1 i}{ }^{m} \cdot X_{1 i} / \sum_{i=0}^{I_{1 i}} U_{1 i}{ }^{m}$ & $I_{1 i}:$ Number of Class 1 \\
$C_{2}=\sum_{i=0}^{I_{2 i}} U_{2 i}{ }^{m} \cdot X_{2 i} / \sum_{i=0}^{I_{2 i}} U_{2 i}{ }^{m}$ & $I_{2 i}:$ Number of Class 2 \\
\hline
\end{tabular}

Fig. 4. Flowchart of the FCM.
$\mathrm{L}_{\mathrm{C} 1}$ and $\mathrm{L}_{\mathrm{C} 2}$ were equal, the estimation maps were classified at the same level in the whole area. Therefore, identifying the water pollution area in the lake is difficult. In this paper, we propose stepwise level slice processing. By performing level slice processing with steps, water quality estimation maps are created without increasing slice levels in advance. When $\mathrm{L}_{\mathrm{C} 1}$ and $\mathrm{L}_{\mathrm{C} 2}$ are equal, the level is divided equally at a new slice level value. After that, the estimation maps are created using the new slice level values. For example, $\mathrm{L}_{\mathrm{C} 1}$ and $\mathrm{L}_{\mathrm{C} 2}$ of $\mathrm{SS}$ values in the May data were equal and classified as level four. Therefore, the level four for SS $(15-25 \mathrm{mg} / \mathrm{l})$ is divided equally at $20 \mathrm{mg} / \mathrm{l}$, and classification areas are 15-20 $\mathrm{mg} / \mathrm{l}$ and 20-25 $\mathrm{mg} / \mathrm{l}$, respectively. At level six, there is no upper limit to the slice level value. The upper limit assumed the maximum value in the water quality data had level six in all the measurement sites. An example of the stepwise level slice processing is shown in Fig. 5.

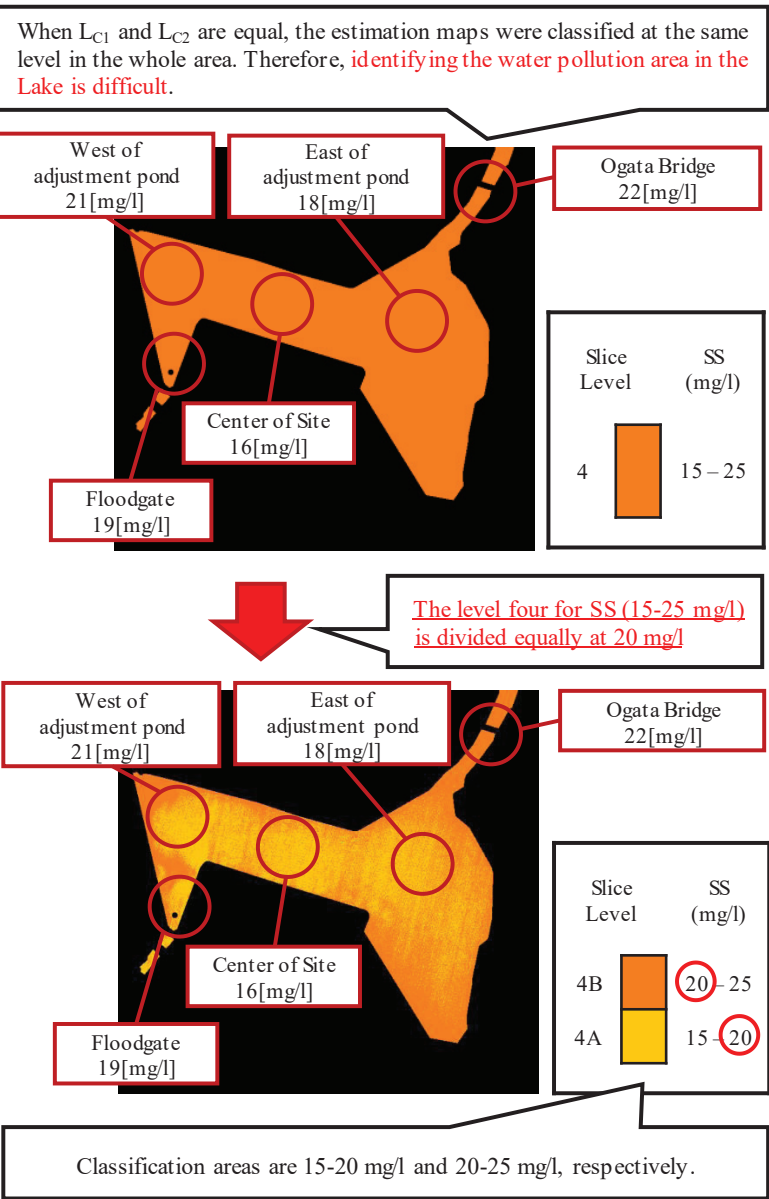

Fig. 5. An example of stepwise level slice processing. (May band 3 data, SS) 


\subsection{Evaluation Criteria of the Estimation Maps by FCM}

To analyze the water quality conditions, we visually compared the estimation maps with the water quality data at the water quality measurement sites. The results are evaluated as follows:

A: FCM results are mainly in agreement with the water quality data: at the four or five measurement sites, the level of FCM results and water quality agree.

B: FCM results are largely in agreement with the water quality data: at the two or three measurement sites, the level of FCM results and water quality agree.

$\mathrm{C}$ : FCM results are not in agreement with the water quality data: (a) at the one measurement site, the level of FCM results and water quality agree, or (b) at all measurement sites, the level of FCM results and water quality do not agree.

\section{Results and Discussion}

\subsection{Estimation Maps by Fuzzy C-Means Clustering}

In this study, selection of $\mathrm{S}_{\mathrm{C} 1}$ and $\mathrm{S}_{\mathrm{C} 2}$ is necessary to create estimation maps by FCM. The following are some of the sites depending on the water quality data. For each water quality data set, a set of the candidate sites was used

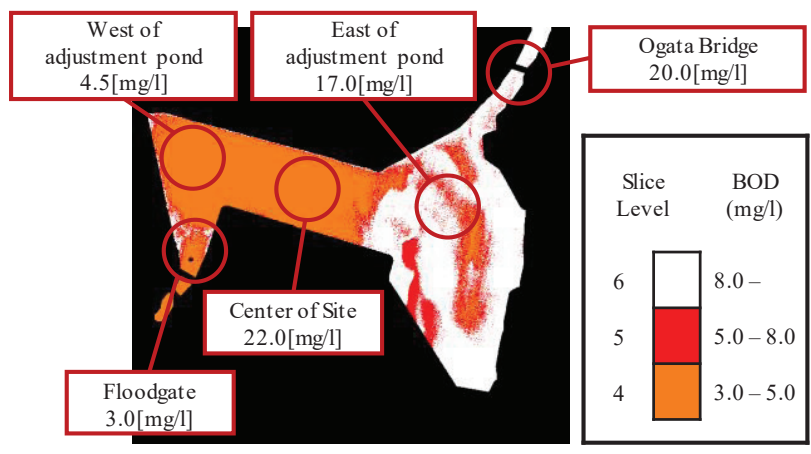

(a) BOD (August band 3 data, $\mathrm{L}_{\mathrm{C} 1}=4, \mathrm{~L}_{\mathrm{C} 2}=6$ ).

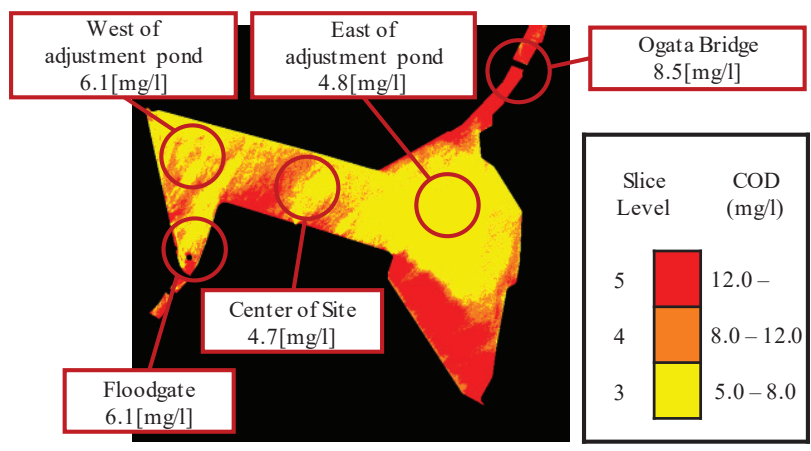

(b) COD (June band 3 data, $\mathrm{L}_{\mathrm{C} 1}=2, \mathrm{~L}_{\mathrm{C} 2}=3$ ).

Fig. 6. Estimation maps by FCM. to create the estimation maps, and a set of the sites that acquired the best estimation maps for analysis was used.

The estimation maps for BOD and COD are shown in Fig. 6. The results using August data are in agreement with the water quality data at Ogata bridge, east of adjustment pond, west of adjustment pond, and Floodgate. The estimation map near an estuary east of the adjustment pond, which received polluted water, is in agreement with the actual pollution condition because the slice level is 6 . The results using June data are in agreement with the water quality data of Ogata bridge, east of the adjustment pond, west of the adjustment pond, and center of the site. The aforementioned indicate that the estimation maps generated by FCM reveal the detailed water quality conditions of Lake Hachiroko.

The estimation maps performed by stepwise level slice processing are shown in Fig. 7. These results for SS using May data show the highest pollution at Ogata bridge, which is in agreement with the water quality data. The estimation maps without stepwise level slice processing are shown in Fig. 8. The results are in agreement with the water quality data, although identifying the water pollution area in the lake is difficult. The above results indicated that FCM with stepwise level slice processing creates water quality estimation maps that identify the pollution area of Lake Hachiroko.

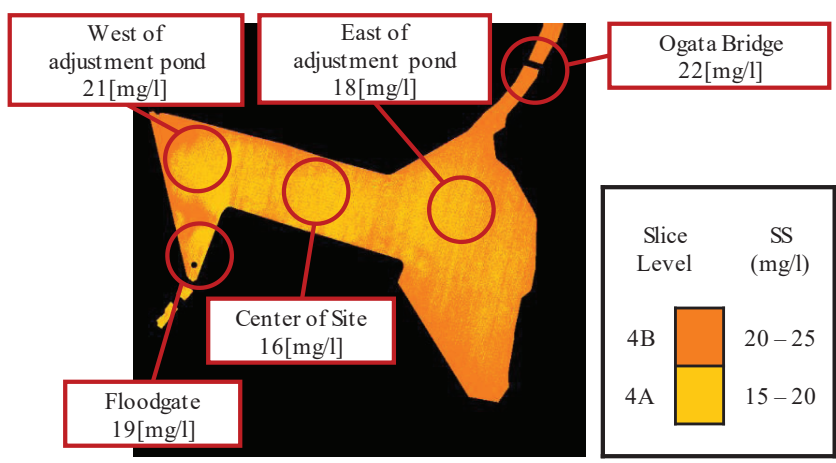

(a) SS (May band 3 data, $\mathrm{L}_{\mathrm{C} 1}=4 \mathrm{~A}, \mathrm{~L}_{\mathrm{C} 2}=4 \mathrm{~B}$ ).

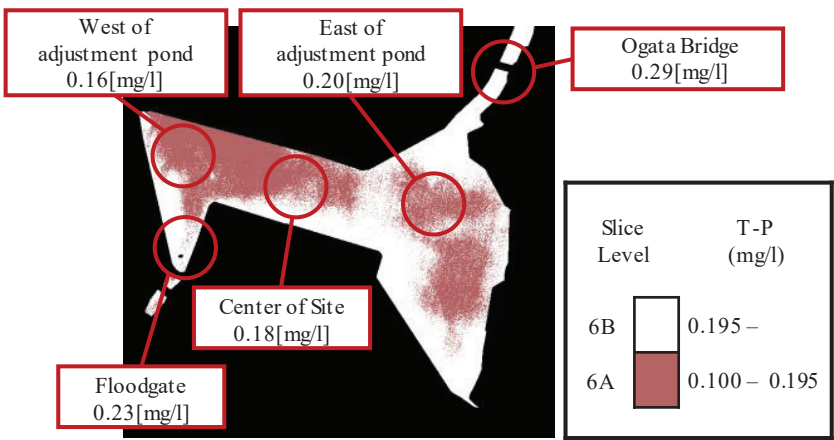

(b) T-P (September band 3 data, $\left.\mathrm{L}_{\mathrm{C} 1}=6 \mathrm{~A}, \mathrm{~L}_{\mathrm{C} 2}=6 \mathrm{~B}\right)$.

Fig. 7. Estimation maps by FCM with stepwise level slice processing. 


\subsection{Analysis of Water Quality Conditions}

Green algae blooms were occurring on the water surface during the acquisition time of August data and September data ${ }^{(6)}$. Water surface information in the May and June data without green algae were different. Therefore, the water quality condition was analyzed by separating the cases in which green algae blooms were occurring and the cases in which they were not. Table 2 lists the comparison results of the estimation maps by FCM and the water quality data. When band 3 (near-infrared) data obtained from the study area with green algae are used, estimation maps by FCM have a strong relationship with BOD, SS, and T-P. On the other hand, when band 1 (visible green) data obtained from the study area without green algae are used, estimation maps by FCM have a strong relationship with COD, SS, and T-N. These results indicate that the above water quality parameters and estimation maps by FCM at each data acquisition time have a correlation.

The levels in T-N, T-P in September data and SS, T-P in May data were included at the one slice level. Since the estimation maps using previous $\mathrm{FCM}^{(4)}$ were classified at the same level in the whole region, understanding the relationship between the results by FCM and the water

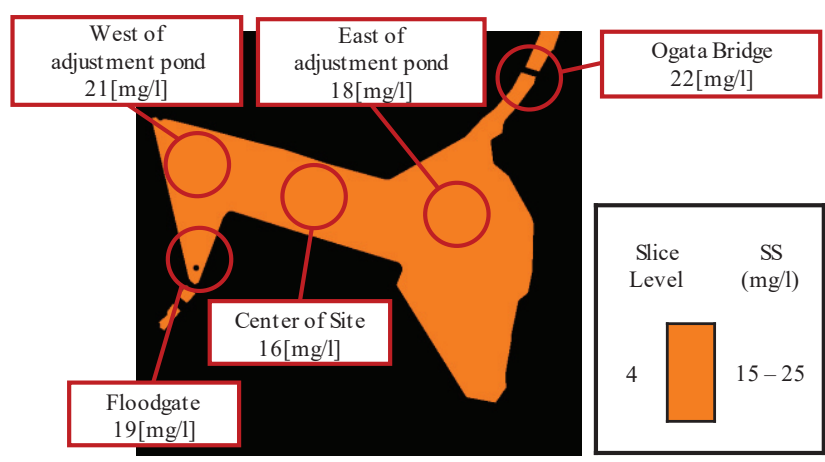

(a) SS (May band 3 data, $\mathrm{L}_{\mathrm{C} 1}=4, \mathrm{~L}_{\mathrm{C} 2}=4$ ).

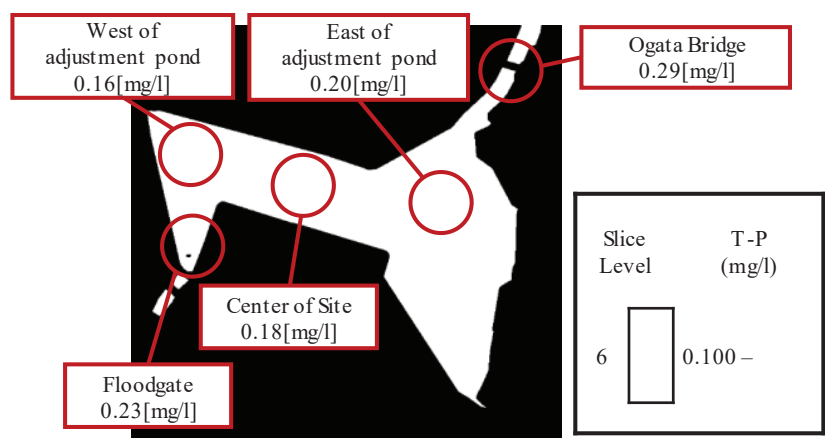

(b) T-P (September band 3 data, $\mathrm{L}_{\mathrm{C} 1}=6, \mathrm{~L}_{\mathrm{C} 2}=6$ ).

Fig. 8. Estimation maps by FCM without stepwise level slice processing. quality parameters was difficult. By performing the proposed stepwise slice level processing, the relative pollution area in Lake Hachiroko were identified and associated with the water quality parameters. Therefore, FCM with stepwise level slice processing is useful for water quality estimation of Lake Hachiroko.

\section{Conclusions}

In this research, we proposed stepwise level slice processing to create water quality estimation maps by FCM. Additionally, to evaluate the usefulness of FCM, we compared the estimation maps with the water quality data. The following conclusions were reached:

Table 2. Results of water quality analysis.

(a) August data.

\begin{tabular}{|l|c|c|c|c|c|}
\hline & \multicolumn{5}{|c|}{ Water quality parameters } \\
\cline { 2 - 6 } & $\begin{array}{c}\text { BOD } \\
(\mathrm{mg} / \mathrm{l})\end{array}$ & $\begin{array}{c}\mathrm{COD} \\
(\mathrm{mg} / \mathrm{l})\end{array}$ & $\begin{array}{c}\mathrm{SS} \\
(\mathrm{mg} / \mathrm{l})\end{array}$ & $\begin{array}{c}\mathrm{T}-\mathrm{N} \\
(\mathrm{mg} / \mathrm{l})\end{array}$ & $\begin{array}{c}\mathrm{T}-\mathrm{P} \\
(\mathrm{m} / \mathrm{l})\end{array}$ \\
\hline Band 1 & $\mathrm{A}$ & $\mathrm{B}$ & $\mathrm{B}$ & $\mathrm{B}$ & $\mathrm{A}$ \\
\hline Band 2 & $\mathrm{A}$ & $\mathrm{B}$ & $\mathrm{A}$ & $\mathrm{B}$ & $\mathrm{A}$ \\
\hline Band 3 & $\mathrm{A}$ & $\mathrm{B}$ & $\mathrm{A}$ & $\mathrm{B}$ & $\mathrm{A}$ \\
\hline
\end{tabular}

(b) September data.

\begin{tabular}{|l|c|c|c|c|c|}
\hline \multirow{2}{*}{} & \multicolumn{5}{|c|}{ Water quality parameters } \\
\cline { 2 - 6 } & $\begin{array}{c}\text { BOD } \\
(\mathrm{mg} / \mathrm{l})\end{array}$ & $\begin{array}{c}\mathrm{COD} \\
(\mathrm{mg} / \mathrm{l})\end{array}$ & $\begin{array}{c}\mathrm{SS} \\
(\mathrm{mg} / \mathrm{l})\end{array}$ & $\begin{array}{c}\mathrm{T}-\mathrm{N} \\
(\mathrm{mg} / \mathrm{l})\end{array}$ & $\begin{array}{c}\mathrm{T}-\mathrm{P} \\
(\mathrm{mg} / \mathrm{l})\end{array}$ \\
\hline Band 1 & $\mathrm{B}$ & $\mathrm{B}$ & $\mathrm{B}$ & $\mathrm{A}$ & $\mathrm{B}$ \\
\hline Band 2 & $\mathrm{B}$ & $\mathrm{B}$ & $\mathrm{B}$ & $\mathrm{A}$ & $\mathrm{B}$ \\
\hline Band 3 & $\mathrm{A}$ & $\mathrm{A}$ & $\mathrm{A}$ & $\mathrm{A}$ & $\mathrm{A}$ \\
\hline
\end{tabular}

(c) May data.

\begin{tabular}{|l|c|c|c|c|c|}
\hline & \multicolumn{5}{|c|}{ Water quality parameters } \\
\cline { 2 - 6 } & $\begin{array}{c}\text { BOD } \\
(\mathrm{mg} / \mathrm{l})\end{array}$ & $\begin{array}{c}\mathrm{COD} \\
(\mathrm{mg} / \mathrm{l})\end{array}$ & $\begin{array}{c}\mathrm{SS} \\
(\mathrm{mg} / \mathrm{l})\end{array}$ & $\begin{array}{c}\mathrm{T}-\mathrm{N} \\
(\mathrm{mg} / \mathrm{l})\end{array}$ & $\begin{array}{c}\mathrm{T}-\mathrm{P} \\
(\mathrm{m} / \mathrm{l})\end{array}$ \\
\hline Band 1 & $\mathrm{A}$ & $\mathrm{A}$ & $\mathrm{A}$ & $\mathrm{A}$ & $\mathrm{B}$ \\
\hline Band 2 & $\mathrm{A}$ & $\mathrm{B}$ & $\mathrm{B}$ & $\mathrm{A}$ & $\mathrm{B}$ \\
\hline Band 3 & $\mathrm{A}$ & $\mathrm{A}$ & $\mathrm{A}$ & $\mathrm{A}$ & $\mathrm{A}$ \\
\hline
\end{tabular}

(d) June data.

\begin{tabular}{|l|c|c|c|c|c|}
\hline \multirow{2}{*}{} & \multicolumn{5}{|c|}{ Water quality parameters } \\
\cline { 2 - 6 } & $\begin{array}{c}\text { BOD } \\
(\mathrm{mg} / \mathrm{l})\end{array}$ & $\begin{array}{c}\mathrm{COD} \\
(\mathrm{mg} / \mathrm{l})\end{array}$ & $\begin{array}{c}\mathrm{SS} \\
(\mathrm{mg} / \mathrm{l})\end{array}$ & $\begin{array}{c}\mathrm{T}-\mathrm{N} \\
(\mathrm{mg} / \mathrm{l})\end{array}$ & $\begin{array}{c}\mathrm{T}-\mathrm{P} \\
(\mathrm{mg} / \mathrm{l})\end{array}$ \\
\hline Band 1 & $\mathrm{B}$ & $\mathrm{A}$ & $\mathrm{A}$ & $\mathrm{A}$ & $\mathrm{A}$ \\
\hline Band 2 & $\mathrm{B}$ & $\mathrm{B}$ & $\mathrm{B}$ & $\mathrm{B}$ & $\mathrm{A}$ \\
\hline Band 3 & B & $\mathrm{A}$ & $\mathrm{B}$ & $\mathrm{B}$ & $\mathrm{B}$ \\
\hline
\end{tabular}

A: FCM results are mainly in agreement with water quality data.

B: FCM results are largely in agreement with water quality data.

$\mathrm{C}$ : FCM results are not in agreement with water quality data. 
(1) FCM with stepwise level slice processing create water quality estimation maps that identify the pollution area of Lake Hachiroko.

(2) The estimation maps generated using the near-infrared data by FCM had a strong relationship with the $\mathrm{BOD}, \mathrm{SS}$, and T-P measured in Lake Hachiroko.

(3) The estimation maps generated using the visible green data by FCM had a strong relationship with the COD, SS, and T-N measured in Lake Hachiroko.

(4) FCM with stepwise level slice processing is useful for water quality estimation of Lake Hachiroko.

We analyzed the water quality conditions using Terra ASTER data with FCM. The result shows that the estimation maps using Terra ASTER data are in agreement with the water quality conditions in Lake Hachiroko. However, the cause of pollution has not been investigated. In the future, we plan to use the data obtained from an unmanned aerial vehicle (UAV) that has higher resolution than Terra ASTER data.

\section{References}

(1) Mohammad Haji Gholizadeh, Assefa Mekonnen Melesse, and Lakshmi Reddi : "A Comprehensive Review on Water Quality Parameters Estimation Using Remote Sensing Techniques", Sensors, Vol. 16, No. 8, Article number 1298, 2016

(2) Yoichi Kageyama, Asako Izumi, Makoto Nishida, and Hiroshi Yokoyama : “Application of Fuzzy C-means for Understanding Water Quality in Lake Hachiroko, Japan", IEEJ Transactions on Electrical and Electronic Engineering, Vol. 11, No. 6, pp. 835-837, 2016

(3) Kai Matsui, Yoichi Kageyama, and Hiroshi Yokoyama : "Analysis of Water Quality of Lake Hachiroko Using Fuzzy C-Means", Journal of Advanced Computational Intelligence and Intelligent Informatics, Vol. 23, No. 3, pp. 456-464, 2019

(4) Kai Matsui, Yoichi Kageyama, and Hiroshi Yokoyama : “Analysis of Water Quality Conditions of Lake Hachiroko, Japan, with Fuzzy C-means Using Terra ASTER Data", Proceedings of the 6th IIAE International Conference on Intelligent Systems and Image Processing 2018, PS-15, 2018
(5) Ministry of the Environment: http://www.env.go.jp/ (Accessed 9 July, 2019)

(6) Akita Prefecture Official Homepage: https://www.pref.akita.lg.jp/ (Accessed 9 July, 2019)

(7) LandBrowser: https://landbrowser.airc.aist.go.jp/landbrowser/index.ht $\mathrm{ml}$ (Accessed 9 July, 2019)

(8) Japan Meteorological Agency: https://www.jma.go.jp/jma/index.html (Accessed 9 July, 2019) 